\title{
Improving subsidiaries' innovation through knowledge inflows from headquarters and peer subsidiaries
}

\author{
Cátia Fernandes Crespo $^{\text {a, }}$, Luis Filipe Lages ${ }^{b}$, Nuno Fernandes Crespo ${ }^{c}$ \\ ${ }^{\text {a }}$ CARME, School of Technology and Management, Polytechnic of Leiria, CSG/ADVANCE, Campus 2, Morro do Lena, Alto do Vieiro 2411 - 901 \\ Leiria, Portugal \\ ${ }^{\mathrm{b}}$ VCW Center at Nova School of Business and Economics, Universidade Nova Lisboa, Portugal \\ ${ }^{\mathrm{c}}$ CSG/ADVANCE, ISEG - Lisbon School of Economics \& Management, Universidade de Lisboa, Rua Miguel Lupi, no. 20, office 314, $1249-078$ \\ Lisbon, Portugal
}

\section{A R T I C L E I N F O}

\section{Keywords:}

Knowledge inflows

MNC

Headquarters

Subsidiaries

Innovation

New product development

\begin{abstract}
A B S T R A C T
This study develops a conceptual model that compares the intensity of the impact of knowledge inflows from peer subsidiaries and from the headquarters in the promotion of a focal subsidiary's innovation activities, moderated by socialization mechanisms and national cultural distance. The authors test hypotheses with a dataset comprised of survey data from 202 multinational corporations (MNC) Portuguese subsidiaries. The results indicate that although knowledge inflows from both the headquarters and peer subsidiaries promote the focal subsidiary's innovations capabilities, headquarters' knowledge transfer is a superior and more efficient source of knowledge in the promotion of a subsidiary's new product development. Moreover, socialization mechanisms, both lateral and vertical integrating mechanisms, act as critical instruments that facilitate the incorporation of the incoming knowledge flows into innovation. This study extends the literature on knowledge transfer in MNCs by exploring how two sources of knowledge transfer, the headquarters and peer subsidiaries, influence a focal subsidiary's new product development, investigating socialization mechanisms and national cultural distance moderating effects.
\end{abstract}

\section{Introduction}

The role of subsidiaries as important contributors in MNCs' knowledge networks has been acknowledged in the literature (Burmeister et al., 2018; Cantwell and Mudambi, 2004; Gupta and Govindarajan, 2000; Noorderhaven and Harzing, 2009). Subsidiaries have been recognized as capable of generating knowledge (Ambos et al., 2006; Frost, 2001; Michailova and Zhan, 2015; Najafi-Tavani et al., 2018; Paterson and Brock, 2002), building their own specific advantages (Birkinshaw et al., 1998; Ghoshal and Bartlett, 1990; Rugman and Verbeke, 2001), becoming centers of excellence (Frost et al., 2002; Moore, 2001) and contributing to innovation activities (Gölgeci et al., 2019; Mudambi, 2002). While these investigations have substantially advanced our knowledge, previous research on knowledge transfer in MNCs has focused mainly on vertical knowledge, that is, flows that take place between the HQ and the subsidiaries (Monteiro et al., 2008; Kumar, 2013). Consequently, few studies have separately analyzed the influences of both HQ (vertical) and peer subsidiaries (horizontal) knowledge transfer (Li and Lee, 2015 and Qin et al., 2017 are a few exceptions). Nevertheless, the

\footnotetext{
* Corresponding author at: Department of Management and Economics, School of Technology and Management, CARME, Polytechnic Institute of Leiria, CSG/ADVANCE, Campus 2, Morro do Lena, Alto do Vieiro, 2411 - 901 Leiria, Portugal.

E-mail addresses: catia.crespo@ipleiria.pt (C.F. Crespo), lflages@novasbe.pt (L.F. Lages), ncrespo@iseg.ulisboa.pt (N.F. Crespo).
} 
increasing demands of competition require knowledge flows in all directions within the MNC network (Birkinshaw and Morrison, 1995) and the conceptualization of subsidiaries as sources of knowledge for the entire MNC is still under-researched and less understood (Michailova and Mustaffa, 2012).

Building on the knowledge-based view and on the concept of the MNC as a network of multiple centers of knowledge (Crespo et al., 2014; Kogut and Zander, 1993; Roth et al., 2009), we conceptualize the MNC as a network of multiple knowledge units, in which subsidiaries can act as critical knowledge hubs, capable of acquiring, converting, and transferring knowledge throughout the entire network. Subsidiaries operate in various environmental contexts and consequently their knowledge is likely to be location bounded and strongly interconnected to each subsidiary's host country. However, an MNC HQ is expected to absorb and configure diverse knowledge flows before intra-organizational sharing with foreign subsidiaries (Li and Lee, 2015). Therefore, since knowledge is intrinsically related to context, incoming knowledge from the HQ and from peer subsidiaries is likely to carry different implications to a focal subsidiary innovation, making a distinct examination between these two sources of knowledge critical. Thus, the present study develops a conceptual model that predicts different effects upon a focal subsidiary innovation for HQ knowledge transfer and for peer subsidiary knowledge transfer, and that investigates different moderator effects.

Since knowledge transfer is a costly and difficult process, understanding the factors that influence the conversion of a subsidiary's incoming knowledge into innovation activities is crucial to the MNC's corporate planning and competitive advantage. MNC managers must recognize which mechanisms need to be applied to leverage the knowledge residing in the intra-MNC network and to integrate and convert these knowledge resources into innovation. Previous research has called attention to the need for future investigation into how corporate parents can structure their relationships with subsidiaries to facilitate innovation (Michailova and Zhan, 2015). To address this issue, the proposed conceptual model analyzes the implementation of socialization mechanisms (lateral and vertical integrating mechanisms) as active elements that an MNC can implement to influence subsidiary knowledge inflows. Since knowledge transfer requires a strong coordination between actors (Hansen, 1999), it becomes crucial for an MNC to foster internal mechanisms that are able to create strong social ties. Socialization mechanisms can stimulate the creation of interpersonal relationships between different MNC units (Björkman et al., 2004), acting as an important facilitator of the knowledge transfer process.

This work contributes to the literature in two ways. First, instead of treating knowledge as a single composite variable and therefore preventing the comprehension of the influence of the different directions of flows, our study extends the literature by comparing the intensity of the impact that both subsidiaries and the HQ exert as sources of new knowledge to peer subsidiaries, leveraging peer subsidiaries' new product development abilities. This analysis is important since it is crucial to an MNC to comprehend which source of knowledge transfer performs a stronger role in a focal subsidiary's new product development capabilities. Second, this work extends the literature by investigating the role of the socialization mechanisms of an MNC in facilitating or hindering vertical and horizontal subsidiary knowledge inflows. This assessment is essential since it remains critical from both a theoretical and managerial perspective to identify the key mechanisms that facilitate the conversion of the incoming knowledge into stronger innovation within an MNC. Thus, we hypothesize that knowledge inflows from both peer subsidiaries and the HQ directly enhance a focal subsidiary's new product development, with a stronger intensity associated to knowledge inflows from the HQ, and that these relationships are moderated by socialization mechanisms and national cultural distance.

We test our hypotheses with a dataset comprised of survey data from 202 Portuguese subsidiaries of MNCs headquartered in North America, Europe, and Japan. We find that although lateral and vertical subsidiary knowledge inflows are important antecedents of a subsidiary's new product development, we detect different intensity of effects. Additionally, both lateral and vertical integrating mechanisms have significant moderator effects, acting as innovation facilitators' factors. Implications of the work are discussed.

\section{Theoretical background}

The knowledge-based view conceptualizes the firm as an institution for integrating knowledge (Grant, 1996; Teece et al., 1997), highlighting that different MNC units, HQ and subsidiaries, possess unique knowledge repositories (Zeng et al., 2018). Consequently, the knowledge-based view emphasizes the need to promote and integrate both vertical and horizontal knowledge transfer (Gölgeci et al., 2019). This literature conceptualizes the MNC as a knowledge-sharing network whose existence is supported by its ability to transfer, generate, and assimilate knowledge more efficiently than markets (Foss and Pedersen, 2004; Kogut and Zander, 1993). However, this argument does not imply that within an MNC intra-corporate knowledge transfers take place in an effective and efficient way (Gupta and Govindarajan, 2000). Consequently, the development of appropriate mechanisms to facilitate the efficient creation, development, and sharing of knowledge constitutes a fundamental challenge in MNCs' knowledge flows management (Fey and Furu, 2008).

The literature on subsidiary knowledge development has placed the focus mainly on relationships outside the MNC. Previous research has strongly concentrated on the contribution of subsidiaries' networking activities in local markets for knowledge development, giving less attention to internal embeddedness (Najafi-Tavani et al., 2015). However, in line with recent studies (e.g., Sheng et al., 2015), we contend that internal MNC relationships are vital since they supply subsidiaries with distinctive knowledge resources. Specifically, we contend that the ability of the subsidiary to actively assimilate the incoming knowledge from different MNC units can facilitate new knowledge generation through new product development processes.

Within the MNC network, a focal subsidiary can obtain knowledge from two separate sources, HQ and peer subsidiaries. HQ knowledge transfers include top-down vertical flows of know-how and skills from the HQ to a focal subsidiary (Ciabuschi et al., 2011). Peer subsidiary knowledge transfers include horizontal knowledge flows moving from one subsidiary to another. Units within an organization possess different types of knowledge and therefore, vertical and horizontal knowledge flows may exert different influences on a focal subsidiary's innovation capability. Vertical and horizontal knowledge flows can influence the depth and breadth of 
a focal subsidiary's knowledge stocks differently (van Wijk et al., 2012). Knowledge depth and breadth are two different dimensions of a firm's knowledge base that reflect both the structure and the content of the existent knowledge (Zhou and Li, 2012). Knowledge depth is defined as the amount of within-field knowledge possessed by a firm (Prabhu et al., 2005; Yang et al., 2017). A firm's knowledge depth reveals the level of complexity and sophistication of its knowledge base in key fields (De Luca and Atuahene-Gima, 2007; Zhou and Li, 2012). Knowledge breadth reflects the range of different domains over which the firm has knowledge (De Luca and Atuahene-Gima, 2007; Yang et al., 2017). Therefore, a firm's knowledge breadth indicates the extent to which the knowledge base contains multiple and distinct domains, capturing the heterogeneous knowledge content (Zhou and Li, 2012). Horizontal knowledge flows tend to broaden a focal subsidiary's knowledge stocks, increasing a focal subsidiary's knowledge breadth. Subsidiaries operate in diverse geographical locations, face a diversity of customer preferences and product markets, and focus on different activities, products, or technologies. Consequently, subsidiaries commonly own knowledge stocks relevant to their specific environment. Therefore, differences between subsidiaries' strategies and activities can restrain horizontal knowledge flows and jeopardize knowledge adaptation to local contexts. Divergences in the contextual elements of knowledge can intensify the uncertainty associated to knowledge transfer and reduce the capacity to assimilate and adapt knowledge. In contrast, HQ are responsible for assimilating knowledge through subsidiaries and leveraging and integrating it throughout the entire organization (Lee et al., 2008). Due to their access to a wide pool of resources and interactions with multiple subsidiaries, HQ frequently acts on knowledge that transcends a focal subsidiary (van Wijk et al., 2012). Therefore, vertical knowledge flows can increase both the depth and breadth of a focal subsidiary's knowledge stocks. Consequently, it is important to analyze these two sources of knowledge transfers separately and to compare their effects on a focal subsidiary's new product development ability.

In the MNC internal network, a low level of natural horizontal dependency between subsidiaries (Roth et al., 2009) and a lack of sense of reliance among the MNC's subsidiaries make the creation of enabling conditions to intra-corporate knowledge transfers critical. Thus, the implementation of the MNC's specific mechanisms to share knowledge can play a vital role in enhancing both the access to and use of knowledge generated in diverse units of an MNC (Noorderhaven and Harzing, 2009). The creation and fortification of personal relationships between managers from different country units can be an excellent vehicle to motivate subsidiaries to seek and share knowledge. Lateral and vertical mechanisms, as socialization processes, can act as vital instruments in the creation of interpersonal relationships between various country units (Björkman et al., 2004), leading to a more intense and profitable knowledge transfer process (Gupta and Govindarajan, 2000). Therefore, our model incorporates the effect of lateral and vertical integrating mechanisms to ascertain their role as creators of enabling conditions to make knowledge from different country units accessible and as motivators of the subsidiaries to seek knowledge.

Moreover, in order to turn the transferred knowledge into value creation, the subsidiaries need to perceive it as appropriate to their specific needs. Subsidiary managers will use and integrate knowledge generated in other markets only if they perceive that it has a potential of being used for competitive advantage (Roth et al., 2009). Managers' perceptions of knowledge generated in other country units are molded by the similarities between their market and the market in which the knowledge originates. Consequently, managers feel more comfortable using marketing and management knowledge emanating from more culturally similar markets (Mäkelä et al.,

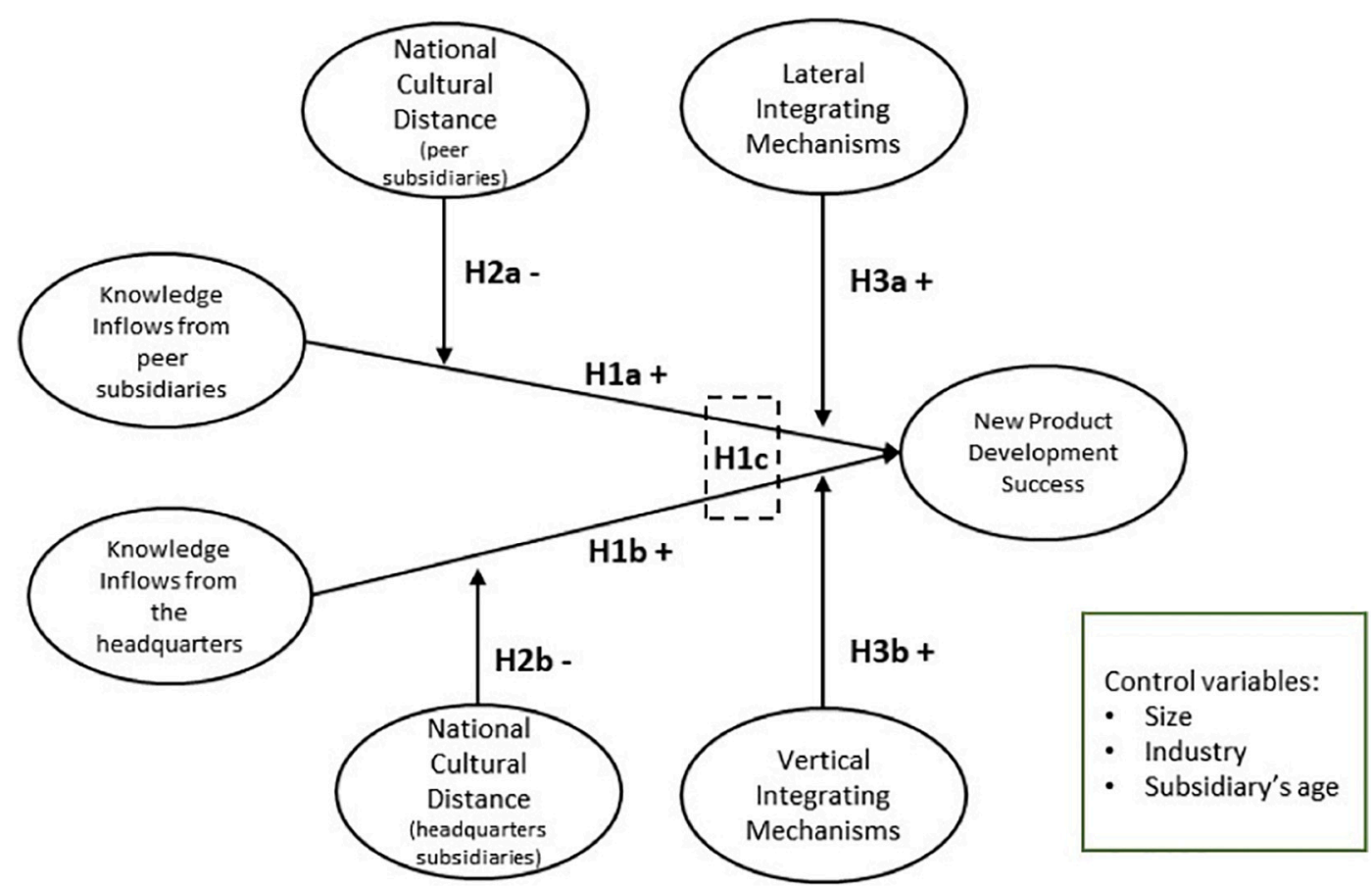

Fig. 1. Consequences and moderator effects of subsidiary knowledge inflows. 
2012). Strong dissimilarities between the source and the recipient market might limit the capability of transforming the incoming knowledge into successful and productive uses suited to the market. Therefore, our model incorporates the effect of national cultural distance between the subsidiary and both the HQ and peer subsidiaries in the knowledge integration process.

We develop a conceptual model (Fig. 1), building on the knowledge-based view of the firm and the literature on knowledge flows (e.g., Nonaka, 1991; Gupta and Govindarajan, 2000). Since knowledge is inherently related to context (Hong and Nguyen, 2009; Li and Lee, 2015), we predict that knowledge inflows from peer subsidiaries and knowledge inflows from the HQ are likely to exert different influences. Therefore, we evaluate the relative importance of lateral and vertical knowledge flows on a focal subsidiary's new product development ability. While lateral and vertical knowledge inflows influence new product development, we contend that these effects are moderated by socialization mechanisms of the MNC, such as lateral and vertical integrating mechanisms, and national cultural distance. In the following section we detail the theoretical arguments relating the constructs within our conceptual model.

\section{Hypotheses}

\subsection{The impact of knowledge inflows on new product development}

A new product development strategy emphasizes the offering of new products distinct from those of main competitors, allowing a foreign firm to achieve organic growth (Zhang et al., 2009). New product development commonly results from diverse knowledge combinations and reflects the innovation's quality, commercialization, and time to market (Bai et al., 2019; Sivadas and Dwyer, 2000). Consequently, the ability to exploit knowledge is fundamental to new product development success (Calantone et al., 2006). Although the important role of subsidiaries in MNCs' knowledge network and innovation has long been recognized (e.g., Bartlett and Ghoshal, 1989; Kotabe et al., 2007), as pointed out by several authors (e.g. Gölgeci et al., 2019; Hansen et al., 2020; Sheng and Hartmann, 2019; Zhang et al., 2009) the relationship between knowledge assimilation and innovation activities in subsidiaries needs further investigation.

Knowledge can be generated in one setting but used in others (Gupta and Govindarajan, 2000). Moreover, since knowledge can be a strategic source for innovation (Capaldo, 2007), leveraging knowledge from its network partners can help a subsidiary to achieve success in new product development. Consequently, we posit that the ability of MNCs to exploit their knowledge globally across subsidiaries can act as an important source of new product development. Previous research has highlighted that knowledge transfer can enhance innovation (Arvanitis and Woerter, 2009), since innovation needs knowledge flows across actors to occur (Gölgeci et al., 2019). Knowledge transfer can enhance a focal subsidiary's knowledge-based competencies (Crespo et al., 2014), which can favor new product development (Vaccaro et al., 2010). Therefore, we argue that knowledge inflows both from peer subsidiaries and the headquarters allow a focal subsidiary to reinforce its knowledge store and learn from other MNC units' experiences, which promotes the focal subsidiary's new product development abilities. More formally:

Hypothesis 1a. Knowledge inflows from peer subsidiaries are positively associated with new product development.

Hypothesis 1b. Knowledge inflows from the HQ are positively associated with new product development.

Subsidiaries face different socio-cultural, legal, and technological environments that contribute to the development of unique knowledge stocks (O'Donnell, 2000). Therefore, their knowledge is likely to be location bounded (Rugman and Verbeke, 2001) since it tends to be more unique and specific to each subsidiary's host country. Although horizontal knowledge flows can help to broaden a focal subsidiary's knowledge stocks and consequently extend the knowledge breadth (van Wijk et al., 2012), the lack of similarities in knowledge's contextual elements can complicate both knowledge transfer and the ability to assimilate and apply the incoming knowledge. The strong degree of heterogeneity of the knowledge components associated to the knowledge breadth might increase the complexity associated to knowledge transfer (De Luca and Atuahene-Gima, 2007). On the other hand, due to their capacity to assimilate knowledge from multiple subsidiaries (Frost et al., 2002; Lee et al., 2008), HQ knowledge transfers can expand both the depth and breadth of a subsidiary's knowledge stocks (van Wijk et al., 2012). The HQ absorbs and integrates knowledge from multiple sources and converts it into knowledge that is less location bounded (Li and Lee, 2015; Rugman and Verbeke, 2001), allowing foreign subsidiaries to exploit it more effectively. Consequently, the HQ knowledge transfers are able not only to expand the different knowledge domains over which the subsidiary has knowledge, but also to deepen the complexity of within-field knowledge that the subsidiary possesses in key fields.

Moreover, subsidiaries need to overcome several corporate and resource constraints to develop lateral relations with peer units of the MNC (Garcia-Pont et al., 2009). The hierarchical structure of an MNC network tends to facilitate knowledge transfer from the HQ to a focal subsidiary, as a mechanism of HQ's control and involvement. Therefore, more frequent interactions of a focal subsidiary with the HQ may provide stronger opportunities to absorb the HQ's knowledge (Li and Lee, 2015). Additionally, due to internal competition for HQ's resources (Ambos and Birkinshaw, 2010), subsidiaries may show less enthusiasm to transfer strategic knowledge resources to peer subsidiaries. Although foreign subsidiaries are increasingly interdependent and with growing levels of cooperation, they continue to compete for internal critical resources, corporate support, and market expansion (Luo, 2005). Therefore, although we consider that knowledge inflows from both the HQ and peer subsidiaries can stimulate a focal subsidiary's new product development, we argue that the effects are stronger for the incoming knowledge from the HQ than from the peer subsidiaries. Thus:

Hypothesis 1c. The positive effect for a focal subsidiary's new product development is stronger for knowledge transfer from HQ than from peer subsidiaries. 


\subsection{The moderating role of national cultural distance}

Cultural distance implies divergences in customer preferences, competition patterns, and business rules between the home and host countries (De Mooij and Hofstede, 2002; Sousa and Tan, 2015). Additionally, it indicates divergences in practices, mindsets, norms, and managerial values (Luo et al., 2001). Within an MNC, as cultural distance increases, the HQ's knowledge of the subsidiary environment and actions is more difficult to obtain, and the subsidiary activities become harder to understand, making behavioral controls by the HQ more difficult (Gong, 2003). Cultural distance decreases the level of comfort and trust between parts, making it more difficult to work together (Hansen and Lovas, 2004), minimizes flows of information and learning (Lyles and Salk, 2007), and complicates management processes between MNC's HQ and subsidiaries (Brock et al., 2000), generating difficult internal relations. However, previous studies have also defended that cultural distance can be a source of value creation leading to learning due to diversity and increasing access to new ideas and a differentiated knowledge base (Vaara et al., 2012).

Although previous studies have predicted ambiguous effects of cultural distance within the knowledge transfer process, in the current study we posit that as cultural distance increases managers face strong difficulties to understand the foreign market precisely, due to the environmental complexity (White III et al., 2013). Since cultural distance indicates strong differences in customer preferences, competition patterns, business rules, and managerial values (De Mooij and Hofstede, 2002; Luo et al., 2001), it may diminish the capacity to interpret and assimilate the incoming knowledge. Managers' perceptions of the foreign incoming knowledge are shaped by the similarities between the source market and the recipient market. Managers feel more comfortable using knowledge originating from more culturally similar markets (Roth et al., 2009). Therefore, strong dissimilarities between the source and the recipient market might restrict the ability of transforming the incoming knowledge into successful and productive uses suited to the market.

In an international network composed of multiple geographically dispersed units, cultural distance can impair the efficiency of knowledge transfer. Knowledge transfer is expected to be difficult between people with distant cultural backgrounds (Mäkelä et al., 2012). National cultural distance can be a source of inefficiency for MNCs (Powell and Lim, 2017), challenging the transfer of management practices (Horwitz et al., 2002) and complicating learning processes. Thus, cultural distance can act as a key obstacle to knowledge transfer due to its capacity to lessen the ability to interpret knowledge and to incorporate it into new productive uses. Therefore:

Hypothesis 2a. The positive effect of knowledge inflows from peer subsidiaries on new product development is stronger as national cultural distance decreases.

Hypothesis 2b. The positive effect of knowledge inflows from the HQ on new product development is stronger as national cultural distance decreases.

\subsection{The moderating role of lateral and vertical integrating mechanisms}

Although knowledge-based view conceptualizes the MNC as a knowledge-sharing network (Foss and Pedersen, 2004), knowledge transfer is not perceived as a purely mechanistic procedure (Gölgeci et al., 2019). Given the intangible, specific, and valuable nature of knowledge (Grant, 1996), knowledge transfer is a demanding and complex procedure across MNC units (Monteiro et al., 2008). Knowledge transfer demands tight coordination and trust between actors (Hansen, 1999), and it is thus imperative to create internal mechanisms that can foster dense and strong social ties.

In the MNC context, corporate socialization can be defined as "the processes through which subsidiary managers' values and norms become closely aligned with those of the parent corporation" (Gupta et al., 1999: 210). Socialization consists of the use of social control mechanisms, intending to elicit organizational identification and the internalization of corporate values and norms in order to lead to cooperative behaviors (Zeng et al., 2018). Corporate socialization mechanisms (which comprise both lateral and vertical integrating mechanisms) stimulate connections and facilitate the development of interpersonal ties within the MNC. Lateral integrating mechanisms include activities that encourage contact between managers of different foreign subsidiaries (O'Donnell, 2000), helping managers to understand the role of each foreign subsidiary in the achievement of the MNC's overall corporate goals. These mechanisms generate increased contact among managers of different internal locations, creating lateral personal networking (Bartlett and Ghoshal, 1993). Vertical integrating mechanisms stimulate the relationship between HQ and subsidiary managers, improving the subsidiary managers' understanding and identification with the HQ perspective (O'Donnell, 2000).

Socialization mechanisms enable the MNC network units, which are geographically dispersed, to interact with each other to share ideas and transfer resources, strengthening the extent of internal relational ties (Claver-Cortés et al., 2018; Lee, 2010). When strong social ties with overseas units of the MNC network are cultivated, a subsidiary is more likely to obtain the resources and market knowledge it lacks to deal with its host environmental challenges (Inkpen and Tsang, 2005; Lee, 2010). We contend that in the MNC context socialization mechanisms can foster subsidiaries' internal embeddedness, facilitating a subsidiary's ability to combine and use the incoming knowledge into innovation activities. Therefore, we argue that lateral and vertical integrating mechanisms can strengthen the effects of peer subsidiaries and HQ knowledge transfer on a focal subsidiary's new product development capacity.

Innovation is perceived as a form of group learning that comprises different intra-organizational units throughout the organization and their reciprocal interactions among knowledge, behavior, and culture (Madhavan and Grover, 1998). Given that innovation is a social process (Madhavan and Grover, 1998), socialization mechanisms are highly important to understand the influence of the MNC's network knowledge flows on a subsidiary's product innovation ability. As such, we theorize that lateral and vertical integrating mechanisms are a crucial organizational instrument that improves the capacity of knowledge inflows to influence the subsidiary's new product development ability. Since knowledge concerning product developments can be more technical and difficult to assimilate 
(Lee, 2010), socialization mechanisms can increase mutual sharing and fortify interactions during the process of knowledge transfer (Hansen and Lovas, 2004), strengthening the impact of knowledge transfer on new product development. More formally:

Hypothesis 3a. The positive effect of knowledge inflows from peer subsidiaries on new product development is stronger when lateral integrating mechanisms are high than when they are low.

Hypothesis 3b. The positive effect of knowledge inflows from the HQ on new product development is stronger when vertical integrating mechanisms are high than when they are low.

\section{Method}

\subsection{Sample and data collection}

This study addresses the impact of a subsidiary's knowledge inflows on new product development. The key informant was the subsidiary's president or general manager. The data were collected through a combination of an online survey and archival data. After an extensive review of literature on MNCs' intra-organizational relationships, the questionnaire was developed. First the survey was prepared in English and then the translation into Portuguese and the back-translation into English were made by two different professional translators (Brislin, 1980; Harzing, 2005). After this process, three academic experts checked for the accuracy of the backtranslated questionnaire through their comparison with the original English version and no major linguistic or conceptual differences were found (Mullen, 1995). Even so, the minor differences were decided through discussion with the translators, in order to ensure that measurement instruments meant the same thing after translation. Subsequently, to evaluate the questionnaire's clarity, it was pretested in 12 face-to-face interviews with subsidiary presidents.

The sample was drawn in 2010 from the financial database SABI, the Iberian Balance Sheet Analysis System, provided by INFORMA D\&B and Bureau Van Dijk. The initial sample contained 1227 multi-industry firms. Following Noorderhaven and Harzing (2009), subsidiaries with fewer than 25 employees were excluded. First, all firms were contacted by telephone to present the purpose of the study, identify key informants (subsidiary presidents), and request their participation. After this procedure, 219 firms were excluded from the initial database: 162 were facing insolvency or were in bankruptcy, and 57 could not participate due to company policy, resulting in a sample of 1008 Portuguese subsidiary firms headquartered in North America, Europe, and Japan.

The final questionnaire was implemented online and its link, accompanied by a personalized text explaining the purpose of the study and providing assurances regarding confidentiality, were sent by e-mail to the presidents of the Portuguese subsidiaries identified. In the first part of the questionnaire the respondent was requested to select a peer subsidiary. A methodological approach similar to Morgan et al. (2004) was followed to guarantee variation in the nature of the relationships selected. Thereby, half of the sample was

Table 1

Final sample characterization.

\begin{tabular}{|c|c|c|}
\hline Characteristics & Frequency & Percentage \\
\hline \multicolumn{3}{|l|}{ Subsidiary size } \\
\hline Less than 50 employees & 83 & 41.1 \\
\hline 50-150 employees & 84 & 41.6 \\
\hline 151-250 employees & 13 & 6.4 \\
\hline More than 250 employees & 22 & 10.9 \\
\hline \multicolumn{3}{|l|}{ Subsidiary age } \\
\hline Less than 5 years & 9 & 4.4 \\
\hline 05-10 years & 33 & 16.3 \\
\hline $11-15$ years & 27 & 13.4 \\
\hline $16-20$ years & 28 & 13.9 \\
\hline $21-30$ years & 65 & 32.2 \\
\hline More than 30 years & 40 & 19.8 \\
\hline \multicolumn{3}{|l|}{ Mode of entry } \\
\hline Acquired subsidiary & 138 & 68.3 \\
\hline Greenfield subsidiary & 64 & 31.7 \\
\hline \multicolumn{3}{|l|}{ Industry } \\
\hline Manufacturing & 143 & 70.8 \\
\hline Non-manufacturing & 59 & 29.2 \\
\hline \multicolumn{3}{|l|}{ HQ home country } \\
\hline Spain & 48 & 23.8 \\
\hline USA & 43 & 21.3 \\
\hline France & 32 & 15.8 \\
\hline Germany & 23 & 11.4 \\
\hline Portugal & 18 & 8.9 \\
\hline Japan & 16 & 7.9 \\
\hline UK & 6 & 3.0 \\
\hline Other European countries & 16 & 7.9 \\
\hline
\end{tabular}


Table 2

Scale items and reliabilities.

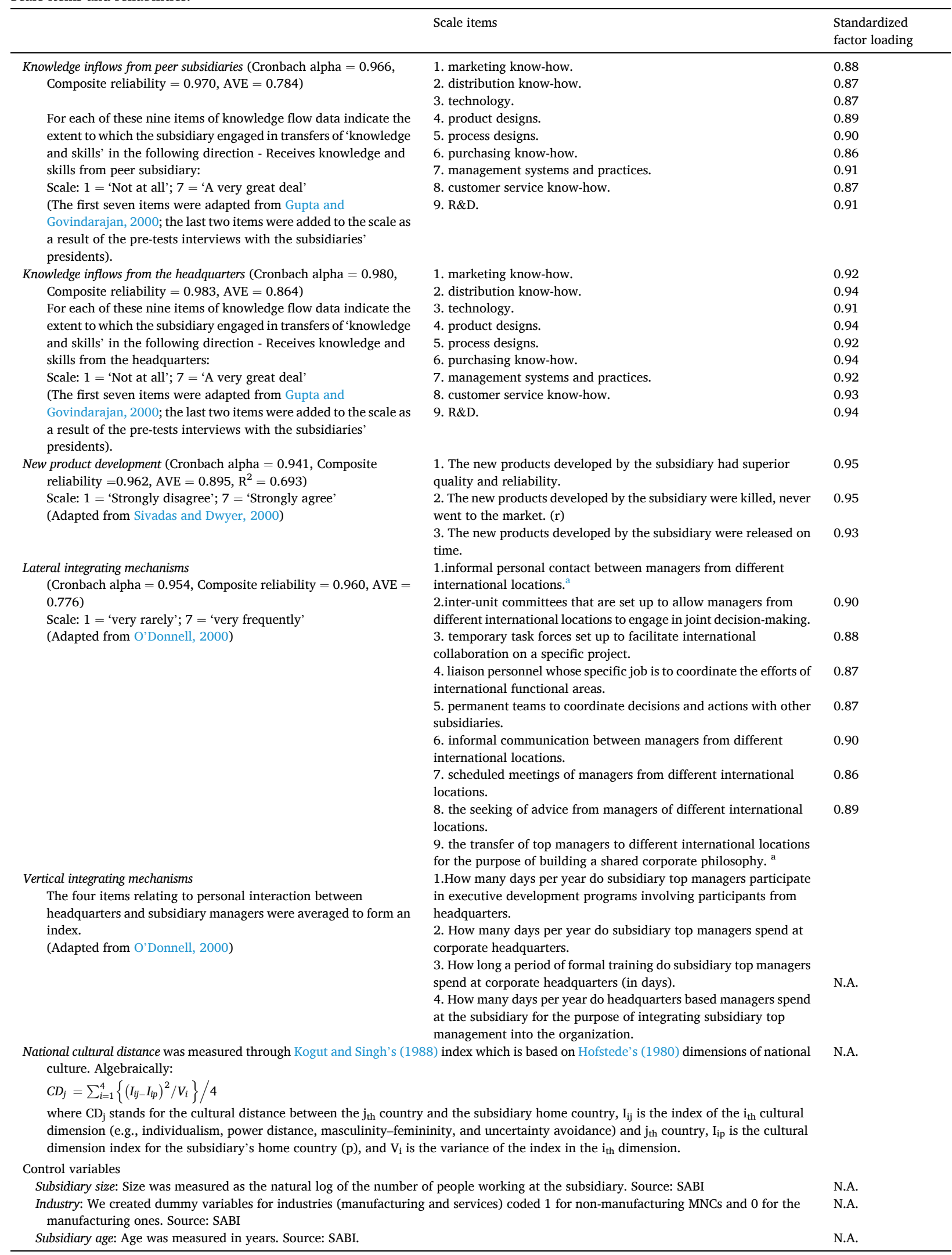


N.A. $=$ not applicable. (r) indicates reverse-coded items.

${ }^{a}$ We deleted this item during the scale purification process.

requested to select a peer subsidiary with which they often interacted, and the other a subsidiary with which they infrequently interacted. Consequently, two versions of the questionnaire were implemented, version A in which managers responded referring to a subsidiary with which they often interacted, and version B in which managers responded referring to a subsidiary with which they infrequently interacted. Versions A and B were attributed randomly to each potential respondent.

We collected 202 usable questionnaires (107 from version A and 95 from version B), an effective response rate of $20 \%$. Respondent subsidiaries averaged 138 employees and 43 million USD in annual sales. The final sample characterization is presented in Table 1.

Nonresponse bias was checked by comparing early and late respondents on all key constructs. We found no significant differences between early and late respondents. We also compared responding and non-responding firms regarding size (number of employees), subsidiary's age, and industry. No significant differences were found on any of the variables. Therefore, nonresponse bias was not considered to be a problem.

Common-method bias was assessed by first examining the data for the presence of a single common factor (Podsakoff, 2003). The data did not adjust to a single factor model. Finally, we conducted Lindell and Whitney's (2001) test, which uses a theoretically unrelated construct (termed a marker variable). The presence of high correlations between the items of the study's principal constructs and the marker variable would indicate common method bias. We used age of the respondents as the marker variable since it was theoretically unrelated to our principal constructs. Common method bias was not a concern as the average correlation between the study's principal constructs and the age of the respondent was low and nonsignificant $(r=0.005$, average $p$-value $=0.635)$.

\subsection{Measures}

Survey measures are presented in Table 2. The measure of knowledge inflows selected in our study observes different complementary knowledge domains from which MNCs' subsidiaries can develop synergies. Knowledge inflow data were collected on the following nine items: marketing know-how, distribution know-how, technology, product designs, process designs, purchasing know-how, management systems and practices, customer service know-how, and R\&D (adapted from Gupta and Govindarajan, 2000). For each item, the key informant was asked to indicate the extent to which the subsidiary engaged in transfers of knowledge, respectively, with peer subsidiaries and with HQ.

A three-item scale (adapted from Sivadas and Dwyer, 2000) was used to measure new product development, focusing on the quality and reliability of the newly developed products, on their ability to reach the market, and on their capacity to be released on time. The measure of lateral integrating mechanisms was adapted from O'Donnell (2000). Respondents were asked to indicate the frequency of informal personal contact between managers from different international locations, inter-unit committees from different international locations to engage in joint decision-making, task forces to facilitate international collaboration, liaison personnel to coordinate the efforts of international functional areas, teams to coordinate actions with other subsidiaries, informal communication between managers from different international locations, scheduled meetings of managers from different international locations, the seeking of advice from managers of different international locations, and the transfer of top managers to different international locations.

Vertical integrating mechanisms were measured through a four-item scale adapted from O'Donnell (2000). Each subsidiary president was asked to indicate: how many days per year subsidiary top managers participate in executive development programs involving participants from HQ, how many days per year subsidiary top managers spend at corporate HQ, how long a period of formal training subsidiary top managers spend at corporate HQ (in days), and how many days per year HQ based managers spend at the subsidiary for the purpose of integrating subsidiary top management into the organization. Following O'Donnell's (2000) procedure, the four items relating to personal interaction between HQ and subsidiary managers were averaged to form an index. National cultural distance between the focal subsidiary and the HQ and between peer subsidiaries was measured through Kogut and Singh's (1988) index. Table 2 contains the main descriptive statistics and correlations among the variables in the research model.

\subsection{Control variables}

To diminish spuriousness of results, other influences that may affect new product development success were included. Specifically, we account for subsidiary size, as larger subsidiaries are expected to possess strong capabilities, subsidiary's age, as older subsidiaries have had more time to develop a knowledge stock (Noorderhaven and Harzing, 2009), and the subsidiary's industry (i.e. manufacturing or services), since industries differ in knowledge intensity and R\&D activities (Gupta and Govindarajan, 2000).

\section{Results}

The model was tested with partial least squares structural equation modelling (PLS-SEM) in Smart PLS 3.0. (Ringle et al., 2015). PLS-SEM is considered an adequate alternative to the covariance-based approaches (Hair et al., 2012).

\subsection{Assessment of the measurement model}

To start the analysis of the adequacy of the model, an individual evaluation of the items was performed. All the standardized factor loadings are greater than 0.70, ensuring convergent validity (Bagozzi and Yi, 1988). To evaluate the measurement model, we assessed 
the internal consistency reliability and convergent validity through Cronbach's Alpha, composite reliabilities and average variance extracted. Cronbach's Alpha values are above the desirable value of 0.70 , demonstrating that the scales are reliable, and the measures used have content validity (Hair et al., 2009). The composite reliability for each construct exceeds the recommend 0.7 and the average variance extracted for each construct is above 0.5 (Table 2). Following Fornell and Larcker's (1981) procedure, evidence of discriminant validity is seen in the fact that the shared variance among any two constructs (i.e., the square of their intercorrelation) is below the average variance explained in the items by the construct - Table 3. We also tested possible collinearity problems by examining variance inflation factors, which in each regression model were below five, demonstrating that multicollinearity was not a concern (Hair et al., 2009).

\subsection{Model fit}

The model fit was assessed following the recommendations of Hair et al. (2012), specifically using the explained variance of the dependent variable $\left(\mathrm{R}^{2}\right)$, the cross-validated redundancy measure $\left(\mathrm{Q}^{2}\right)$, and the effect size $\left(\mathrm{f}^{2}\right)$. Furthermore, the standardized root mean square residual (SRMR) introduced by Henseler et al. (2014) was determined.

Regarding the evaluation of the structural model using $\mathrm{R}^{2}$, the level of explained variance of each endogenous variable should exceed 10\% (Falk and Miller, 1992). The model predicted $69.3 \%$ of the new product development variance. Therefore, this condition is confirmed for the endogenous variable.

A cross-validated redundancy measure $Q^{2}$ greater than zero for the endogenous constructs supports predictive relevance (Hair et al., 2012). To calculate the cross-validated redundancies, we used a blindfolding procedure containing 7 as omission distance (Hair et al., 2012). The endogenous construct presents a cross-validated redundancy $\mathrm{Q}^{2}$ value greater than zero (new product development 0.480), which indicates the model's predictive power.

In addition to the explained variance of the dependent variable $\left(\mathrm{R}^{2}\right)$ and the cross-validated redundancy measure $\left(\mathrm{Q}^{2}\right)$, to evaluate the explanatory power of the structural model we computed the effect size $\left(\mathrm{f}^{2}\right)$ of each independent variable on the endogenous variable. Guidelines for evaluating $\mathrm{f}^{2}$ are that values of $0.02,0.15$, and 0.35 , indicate respectively, small, medium and large effects (Cohen, 1988) of the exogenous latent variable. We found that knowledge inflows from peer subsidiaries have a moderate effect size on new product development $\left(\mathrm{f}^{2}=0.185\right)$. Knowledge inflows from the HQ exert a moderate effect size on new product development $\left(\mathrm{f}^{2}\right.$ $=0.238$ ).

Moreover, regarding the model fit, the standardized root mean square residual (SRMR) was used, which is defined as the difference between the observed correlation and the model's implied correlation matrix. This measure allows evaluating the average magnitude of the discrepancies between observed and expected correlations as an absolute measure of model fit criterion. Henseler et al. (2014) introduce the practice of using the SRMR as a goodness of fit measure for PLS-SEM to avoid model misspecification. A value less than 0.10 (or of 0.08 in a more conservative version) indicates a good fit (Hu and Bentler, 1999). The SRMR of 0.036, indicates that the model presents a good fit.

Finally, in international business research the statistical power of SEM models has been considered a key issue (Brock, 2003; Ellis, 2010; Zhan, 2013). Even though the model developed in this study is quite complex, we consider that our sample size ( $n=202)$ is suitable for obtaining the recommended statistical power of 0.8 (Hair et al., 2009; Ellis, 2010; Zhan, 2013), due to several reasons. First, this study surpasses the threshold ratio of 10:1 between the observations and the independent variables (Chin, 2010). Even if all operational variables necessary to test the moderation effects are considered simultaneously, this ratio is higher than the desired value of 20:1 suggested by Hair et al. (2009), fulfilling possible overfitting concerns. Second, by equating the characteristics of our model (n $=202$; high loadings ranging between 0.86 and 0.95 ; an average of 7 indicators per variable; medium effect sizes) with the results of

Table 3

Correlation matrix and descriptive statistics of measures.

\begin{tabular}{|c|c|c|c|c|c|c|c|c|c|c|c|c|}
\hline & Mean & $\begin{array}{l}\text { Standard } \\
\text { deviation }\end{array}$ & 1 & 2 & 3 & 4 & 5 & 6 & 7 & 8 & 9 & 10 \\
\hline $\begin{array}{l}\text { 1.Knowledge inflows from peer } \\
\text { subsidiaries }\end{array}$ & 3.40 & 1.65 & 0.89 & & & & & & & & & \\
\hline $\begin{array}{l}\text { 2. Knowledge inflows from } \\
\text { headquarters }\end{array}$ & 4.12 & 2.02 & 0.64 & 0.93 & & & & & & & & \\
\hline 3. New product development & 4.39 & 1.70 & 0.66 & 0.69 & 0.95 & & & & & & & \\
\hline 4. Lateral integrating mechanisms & 5.45 & 1.33 & -0.03 & 0.00 & -0.08 & 0.98 & & & & & & \\
\hline 5. Vertical integrating mechanisms & 14.65 & 13.05 & 0.25 & 0.32 & 0.30 & 0.12 & N.A. & & & & & \\
\hline $\begin{array}{l}\text { 6. National cultural distance peer } \\
\text { subsidiaries }\end{array}$ & 1.66 & 1.6 & -0.45 & -0.43 & -0.58 & -0.04 & -0.22 & N.A. & & & & \\
\hline $\begin{array}{l}\text { 7. National cultural distance } \\
\text { subsidiary-headquarters }\end{array}$ & 2.12 & 1.68 & -0.55 & -0.60 & -0.67 & -0.01 & -0.25 & 0.47 & N.A. & & & \\
\hline 8. Subsidiary size (log) & 1.86 & 0.44 & 0.04 & -0.13 & -0.13 & -0.05 & -0.12 & -0.01 & 0.10 & N.A. & & \\
\hline 9. Industry & N.A. & N.A. & 0.05 & 0.12 & 0.03 & -0.04 & -0.08 & -0.04 & -0.05 & -0.19 & $\begin{array}{l}\text { N. } \\
\text { A. }\end{array}$ & \\
\hline 10. Subsidiary age & 26.9 & 23.5 & -0.01 & 0.04 & 0.04 & 0.02 & -0.03 & -0.04 & -0.02 & 0.10 & 0.04 & $\begin{array}{l}\mathbf{N} \\
\text { A. }\end{array}$ \\
\hline
\end{tabular}

Notes: The diagonal shows the square roots of the AVE; N.A. = not applicable. 
the Monte Carlo's simulations developed by Reinartz et al. (2009), in which they compare the statistical power of covariance-based SEM and PLS-SEM, we obtain statistical power values above the recommended threshold of 0.80 (Zhan, 2013). Third, to enhance the confidence in our findings, and in line with the suggestion of Hair et al. (2009), we computed post-hoc tests for both direct predictors with the $\mathrm{G}^{*}$ Power 3.1.9.7 software (Faul et al., 2009). Considering the sample size, the two-tailed test with $\alpha=0.05$, the number of predictors, and the effect size for both direct predictors (the knowledge inflows from peer subsidiaries, $\mathrm{f}^{2}=0.185$, and the knowledge inflows from the headquarters, $\mathrm{f}^{2}=0.238$ ), the statistical power is 1.0 in both cases.

\subsection{Structural model estimation}

A bootstrapping procedure of 5000 subsamples was used to assess the parameter estimates' significance (Hair et al., 2012). Results show that the knowledge inflows from peer subsidiaries are positively associated with new product development $(\beta=0.17, p<0.01)$, supporting $\mathrm{H}_{1 \mathrm{a}}$ (Table 4). Knowledge inflows from the HQ are positively related to new product development $(\beta=0.24, p<0.001)$, supporting $\mathrm{H}_{1 \mathrm{~b}}$. The positive effect of knowledge inflows on new product development is stronger for HQ knowledge transfer than for peer subsidiary knowledge transfer, supporting $\mathrm{H}_{1}$. The effect size of knowledge inflows from the HQ on new product development $\left(\mathrm{f}^{2}\right.$ $=0.238)$ is superior to the effect size of knowledge inflows from peer subsidiaries on new product development $\left(\mathrm{f}^{2}=0.185\right)$. To further improve the reliability of our results, we followed the approach of a nonparametric bootstrapping for path differences suggested by Chin et al. (2013) and ran 5000 percentile bootstrap samples of the model. The difference between those two coefficients was confirmed by the $p$-value estimate $(\mathrm{p}<0.001)$.

The interaction term for knowledge inflows from peer subsidiaries and national cultural distance between peer subsidiaries is not significant, thus not supporting $\mathrm{H}_{2 \mathrm{a}}$. The interaction term for knowledge inflows from the HQ and national cultural distance between the HQ and the subsidiary is also not significant, therefore not supporting $\mathrm{H}_{2 \mathrm{~b}}$.

The moderator effect of lateral integrating mechanisms on the relationship between knowledge inflows from peer subsidiaries and new product development is as predicted $(\beta=0.13, \mathrm{p}<0.01)$, thus supporting $\mathrm{H}_{3 \mathrm{a}}$. The interaction term for knowledge inflows from the HQ and vertical integrating mechanisms is positively related to new product development $(\beta=0.08, p<0.05)$, thus supporting $\mathrm{H}_{3 \mathrm{~b}}$.

To gain further insight into the moderation effects we plotted the interactions and conducted simple slope tests. The simple slope test involved splitting the moderator variable - lateral integrating mechanisms - into a high group (one standard deviation greater than the mean) and a low group (one standard deviation less than the mean), and re-estimating the relationship between knowledge inflows

Table 4

Structural model results.

\begin{tabular}{|c|c|c|}
\hline Variables & Hypotheses & Results \\
\hline \multicolumn{3}{|l|}{ Control variables } \\
\hline Size & & $\begin{array}{l}0.05 \\
(0.63)\end{array}$ \\
\hline Industry & & $\begin{array}{l}0.06 \\
(0.78)\end{array}$ \\
\hline Subsidiary age & & $\begin{array}{l}-0.01 \\
(0.22)\end{array}$ \\
\hline \multicolumn{3}{|l|}{ Independent variables } \\
\hline Knowledge inflows (lateral) $\rightarrow$ NPD & $\mathrm{H}_{1 \mathrm{a}}$ & $\begin{array}{l}0.17 \\
(2.94)^{* *}\end{array}$ \\
\hline Knowledge inflows (vertical) $\rightarrow$ NPD & $\mathrm{H}_{1 \mathrm{~b}}$ & $\begin{array}{l}0.24 \\
(3.51)^{* *}\end{array}$ \\
\hline National Cultural Distance peer subsidiaries $\rightarrow$ NPD & & $\begin{array}{l}-0.25 \\
(4.72)^{*}\end{array}$ \\
\hline National Cultural Distance headquarters-subsidiary $\rightarrow$ NPD & & $\begin{array}{l}-0.28 \\
(5.28)^{\text {*k }}\end{array}$ \\
\hline Lateral integrating mechanisms $\rightarrow \mathrm{NPD}$ & & $\begin{array}{l}-0.09 \\
(1.79)\end{array}$ \\
\hline Vertical integrating mechanisms $\rightarrow$ NPD & & $\begin{array}{l}0.05 \\
(1.02)\end{array}$ \\
\hline \multicolumn{3}{|l|}{ Relevant interaction effects } \\
\hline Knowledge inflows (lateral) $x$ national cultural distance $\rightarrow$ NPD & $\mathrm{H}_{2 \mathrm{a}}$ & $\begin{array}{l}-0.01 \\
(0.18)\end{array}$ \\
\hline Knowledge inflows (vertical) $x$ national cultural distance $\rightarrow$ NPD & $\mathrm{H}_{2 \mathrm{~b}}$ & $\begin{array}{l}0.07 \\
(1.47)\end{array}$ \\
\hline Knowledge inflows (lateral) $x$ lateral integrating mechanisms $\rightarrow$ NPD & $\mathrm{H}_{3 \mathrm{a}}$ & $\begin{array}{l}0.13 \\
(3.12)^{* *}\end{array}$ \\
\hline Knowledge inflows (vertical) $x$ vertical integrating mechanisms $\rightarrow$ NPD & $\mathrm{H}_{3 \mathrm{~b}}$ & $\begin{array}{l}0.08 \\
(2.04)^{*}\end{array}$ \\
\hline
\end{tabular}

\footnotetext{
We report standardized regression coefficients (t-values are in parentheses). We used a two-tailed test for all hypotheses.

" $p<0.05$.

${ }^{* *} p<0.01$.

$p<0.001$.
} 
from peer subsidiaries and new product development. The plot in Fig. 2, Panel A, shows that when lateral integrating mechanisms are high, the positive relationship between knowledge inflows from peer subsidiaries and new product development is stronger (simple slope: $\beta=0.749, t=10.96, \mathrm{p}<0.001$ ) than when it is low (simple slope: $\beta=0.648, t=4.78, \mathrm{p}<0.001$ ). Fig. 2 , Panel $\mathrm{B}$, shows a positive relationship between knowledge inflows from the HQ and new product development (simple slope: $\beta=0.966, t=7.19, \mathrm{p}<$ 0.001 ) when vertical integrating mechanisms are high. There is no relationship between the two constructs when vertical integrating mechanisms are low (simple slope: $\beta=0.209, t=1.23$, n.s.).

\section{Discussion}

This study investigated the intensity of the effect of knowledge inflows, from both the HQ and the peer subsidiaries on a subsidiary's new product development, moderated by socialization mechanisms and national cultural distance. We find that both internal sources of knowledge transfer, HQ and peer subsidiaries, positively enhance a focal subsidiary's new product development ability, although at different rates. Previous research has predominantly investigated the influence of HQ's knowledge transfer, neglecting the role and importance of peer subsidiaries' knowledge transfers. This research extends previous literature by analyzing both sources of knowledge transfers in a single study. Contrary, to Zhang et al. (2019), who concluded that only the knowledge flows between the HQ and subsidiaries, in contrast to flows between peer subsidiaries, contribute to MNC innovative results, our study reveals that both sources of knowledge are crucial in the development of a focal subsidiary's innovation ability. Our findings demonstrate that a subsidiary's new product development relies on its assimilation and integration of knowledge from both the HQ and peer subsidiaries, providing evidence of the strategic value of knowledge resources as envisioned under the knowledge-based view. Therefore, there can be multiple centers of knowledge within an MNC that can act as knowledge diffusers. Results demonstrate that knowledge inflows take place vertically and horizontally, suggesting that MNCs are characterized more by an interdependent structure than by a hierarchical one (a point of debate in the literature). Our study extends the current literature by demonstrating that the transfer of subsidiaries' knowledge stocks to their "sister" units becomes a source of innovation for peer units within the corporation.

However, although peer subsidiaries perform important roles as sources of knowledge generation and dissemination, the current study's results reveal that the HQ continues to act as the main critical hub in the subsidiary's knowledge integration process. Results demonstrate that HQ's knowledge transfer is a more effective and efficient source of knowledge in the process of a focal subsidiary's new product development. Although horizontal knowledge flows can increase the breadth of a focal subsidiary's knowledge stock, differences in knowledge contextual elements appear to reduce the capacity to assimilate and use knowledge. Expanding the knowledge stock breadth enables subsidiaries to receive new valuable knowledge, increasing the range of domains over which the

A: Moderating effect of lateral integrating mechanisms

Interaction of lateral integrating mechanisms and knowledge inflows from peer subsidiaries on new product development

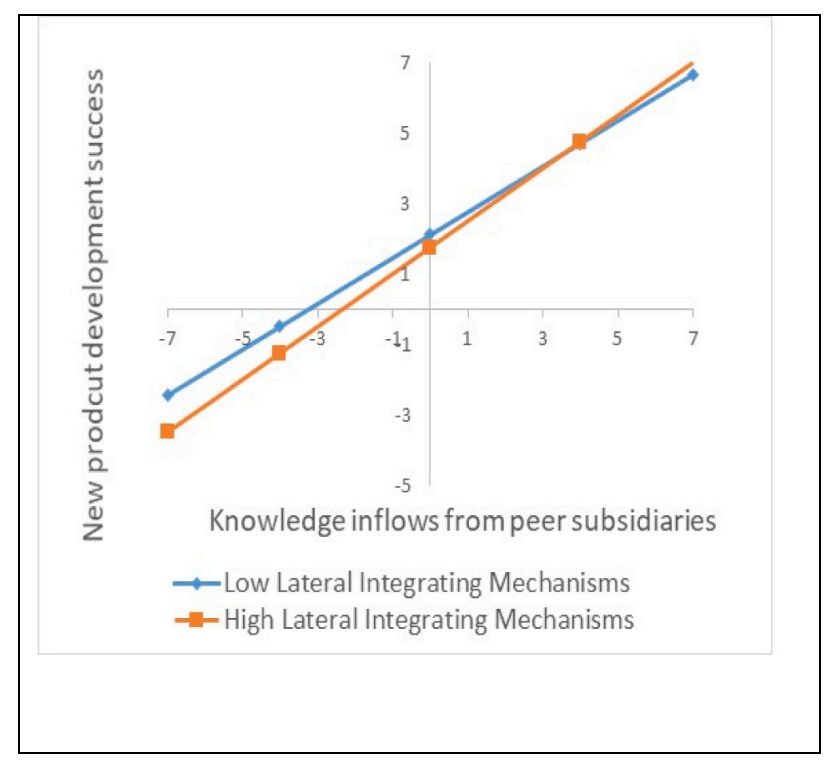

B: Moderating effect of vertical integrating mechanisms

Interaction of vertical integrating mechanisms and knowledge inflows from the headquarters on new product development

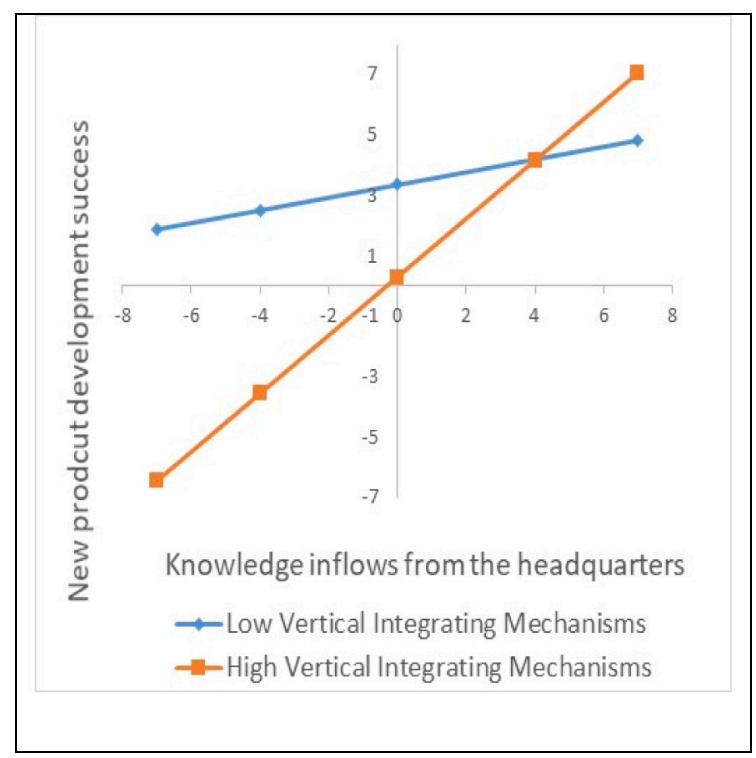

Fig. 2. Interaction effects. 
subsidiary has knowledge. However, our results suggest that the challenge of assimilation of diverse and heterogeneous information can make more difficult the subsidiary's ability to identify the value of the new acquired knowledge, integrate it, and combine it with existing knowledge in order to use it in innovation activities. Divergences between subsidiaries' strategies and activities within the MNC network and in the contextual elements of knowledge can hamper the subsidiary's capacity to assimilate and adapt the incoming knowledge. On the contrary, the capacity of vertical knowledge flows to increase both the depth and breadth of a focal subsidiary's knowledge stock exerts a stronger effect on a subsidiary's new product development ability. Thus, the increase of a focal subsidiary's knowledge stock depth can be better aligned with enhancing existing knowledge required to improve the innovation abilities. Therefore, the HQ knowledge transfers may be able to increase the complexity of within-field knowledge that a subsidiary possesses in key strategic areas, taking into consideration the position of the subsidiary within the MNC network. Additionally, during the course of daily operations, HQ faces frequent opportunities to exchange knowledge with foreign subsidiaries. However, communications tend to be less common between peer subsidiaries, which may restrain both the motivation and capacity to share knowledge on a lateral basis. Moreover, different strategic focuses and positions of the foreign subsidiaries within the MNC network may provoke cultural conflicts and tension between peer subsidiaries (Li and Lee, 2015). The MNC is a differentiated network of subsidiaries that both compete and cooperate (Ghoshal and Bartlett, 1990). Subsidiaries are persuaded to simultaneously cooperate and compete for internal critical resources (Luo, 2005). Although HQ stimulates inter-subsidiaries' collaboration, they also induce inter-subsidiaries' competition for efficiency purposes. This tensional duality constitutes a major challenge for internal knowledge transfers.

Although knowledge transfers across national boundaries are perceived as an organizational imperative for MNCs (Sheng et al., 2015), intra-corporate knowledge flows, especially among the dispersed geographic locations of an MNC, can suffer from substantial friction and inefficiency (Bartlett and Ghoshal, 1989). Therefore, we focus on examining the conditions that stimulate the effective use of knowledge within the MNC network. Lateral and vertical integrating mechanisms reinforce the subsidiary's knowledge integrative capacity by helping to translate these incoming knowledge flows into innovation. This knowledge assimilation facilitated through socialization mechanisms is required to generate new knowledge linked to the innovation value chain. Multinational corporations that are better able to stimulate intra-corporate knowledge transfer are more effective at increasing their subsidiaries' innovation abilities. To foster a subsidiary's product innovation ability, MNC managers should nurture socialization mechanisms, not only between HQ and subsidiaries, but also between peer subsidiaries in order to aid the transfer and integration of intra-corporate knowledge.

When investigating the role of national cultural distance we found no significant moderator effect on the influence of lateral and vertical knowledge inflows on a subsidiary's new product development. Although it was expected that national cultural distance could reduce the capacity to interpret and assimilate the incoming knowledge (De Mooij and Hofstede, 2002), we can argue that these difficulties can be overcome through the use of lateral and vertical integrating mechanisms as important factors to enable a foreign subsidiary to use and integrate the incoming knowledge into new product development. This argument is aligned with the recent results of Alofan et al. (2020), who found that national cultural distance may not necessarily act as a barrier to management innovations within MNCs since organizational culture can offset national cultural distance effects. Organizational cultural differences, translated into divergences in corporate beliefs, norms, and values, can be a significant obstacle to knowledge transfer (Vaara et al., 2012). However, corporate socialization mechanisms help to align corporate values and norms and promote organizational identification (Gupta et al., 1999), thereby attenuating organizational culture differences. The non-significant moderator effect of national cultural distance suggests that a common set of organizational values, beliefs, and norms can perform a more substantial role in the ability to integrate the incoming knowledge into new product development than can national cultural differences. This finding suggests that MNCs might be able to mitigate negative national cultural distance effects on knowledge transfer by strengthening socialization mechanisms.

\section{Conclusions}

\subsection{Contributions}

This study highlights that a focal subsidiary's innovation activities are explained by its internal embeddedness. Internal embeddedness allows the subsidiaries to receive and leverage knowledge from the HQ and from other subsidiaries, upgrading their new product development abilities. Our results are in contrast with previous studies reporting that a subsidiary's internal embeddedness does not directly contribute to the impact on innovation (Ciabuschi et al., 2011) and that internal embeddedness negatively influences a subsidiary's importance for product development in the MNC (Yamin and Andersson, 2011). Our findings show that MNC internal embeddedness is critical for knowledge processes to create value for a subsidiary's new product development. This result is consistent with Gölgeci et al. (2019), who predicted that internal embeddedness and the development of internal knowledge transfer mechanisms can improve MNC subsidiaries' innovation.

This study improves our understanding of subsidiaries' new product development process by comparing the intensity of the impact of both peer subsidiaries and the HQ as sources of a focal subsidiary's new knowledge. Although we conceptualize the MNC as a differentiated network, with multiple knowledge sources, our results provide evidence that even so, the HQ remains the most important source of knowledge within the MNC. The preferential position of the HQ allows a favored access to absorb new knowledge from the internal network and consequently to disseminate it to the rest of the MNC. During recent decades, some subsidiaries have gradually shifted from a position of knowledge dependency on the HQ to one of being an active knowledge creator and contributor of the internal knowledge network (Zhang et al., 2019). However, the existence of strong differences between subsidiaries' knowledge contextual elements, as well as the internal rivalries and competition tensions between peer subsidiaries, may still constitute an obstacle to the occurrence of stronger lateral knowledge flows. Consequently, the HQ continues to perform a critical role in the MNC's 
competence building, with the ability to expand both the depth and breadth of a subsidiary's knowledge stocks. This position is achieved due to the HQ's advantages of recognizing the importance of the newly incoming knowledge and of selecting which of this new knowledge should be further explored and disseminated (Zhang et al., 2019).

Our findings contribute to the knowledge-based view by emphasizing that MNCs may require effective knowledge transfer mechanisms across units to leverage resources for innovation. Previous research has detected that one drawback of knowledge transfer for many MNCs is the over-reliance on technology processes in detriment to interpersonal processes (Roth et al., 2009). Our results demonstrate that socialization mechanisms are crucial facilitators in the process of transforming the integrated knowledge into innovation, since they act to build interpersonal familiarity and personal affinity among personnel from different subsidiaries (Gupta and Govindarajan, 2000). Therefore, socialization allows the creation of tight coupling between people from different units of the MNC (Hansen, 1999), which is fundamental to leverage knowledge transfer outcomes.

Today we observe foreign subsidiaries increasingly acting not only as knowledge receivers but as knowledge creators within the MNC network (Achcaoucaou et al., 2014). Our findings show the existence of an internal MNC network in which knowledge flows take place in both vertical and lateral directions. This subsidiaries' capacity to generate knowledge for the whole MNC comes closer to the heterarchical (Hedlund, 1986) and transnational (Bartlett and Ghoshal, 1989) conceptualization of an MNC. However, our findings highlight that although subsidiaries are playing an increasingly active role in knowledge dissemination and innovation activities, their knowledge transfer contribution to peer subsidiaries innovation abilities remains below HQ's involvement.

\subsection{Managerial implications}

Our results highlight that through the implementation of integration mechanisms, HQ managers can play a vital role in the intensification of the internal knowledge network, which is essential to innovation efforts. The lower intensity of knowledge flows between peer subsidiaries suggests that the HQ managers may be able to play a dynamic role within the MNC network to mitigate both the current lack of motivation and reluctance to inter-subsidiary knowledge transfers. This implies that as a complement to the definition of efficiency objectives for subsidiaries to promote competition, managers should also outline specific goals regarding cooperation actions and knowledge transfer across peer subsidiaries. They also need to implement organizational structures and behavioral mechanisms that are supportive for cross-border knowledge transfer, to foster cross-functional cooperation and intraorganizational trust. The growing dispersion of knowledge creation activities across MNC units and the increased need to effectively source and share knowledge through internal networks indicates that the traditional roles of subsidiaries and HQ need to be rethought (Scott-Kennel and Saittakari, 2019). Therefore, MNCs should expand and reinforce socialization mechanisms to improve the knowledge transfer effectiveness.

Without MNC socialization mechanisms, firm specific advantages may remain location-bound at the subsidiary. Lateral and vertical integrating mechanisms facilitate the conversion of knowledge inflows into innovation actions. Units that are strongly tied to one another are more able to convert the incoming knowledge into productive outcomes. MNCs should stimulate inter-unit committees, international task forces, long and short-term visits, personal communications, face to face meetings, shared training, and executive development programs involving members of both HQ and subsidiaries to intensify inter-unit communication, build trust, align interests and visions, and improve the sharing of cross-border knowledge. These integrating mechanisms may aid less experienced subsidiary and HQ managers in developing abilities to identify and explore opportunities to share cross-border knowledge during interunit interactions, as well as in preventing more experienced managers from developing the not-invented here syndrome, thereby neglecting opportunities to absorb and explore new knowledge. Strong ties can enhance trust, create a shared identity, and generate the cohesion necessary to foster the subsidiaries' willingness to transfer knowledge with other organizational units.

\subsection{Limitations and future research}

Although this work substantially advances our understanding of subsidiaries' vertical and horizontal knowledge inflows, it is not without limitations. First, although we were able to capture vertical and horizontal knowledge inflows, we measured these from the subsidiary itself. While we believe this accurately reflects subsidiary knowledge inflows, it does not capture knowledge outflows that match those inflows. Therefore, the collection of dyadic data would greatly enhance the findings of this study. A second limitation is that we examined the relationships with cross-sectional data only. It would be worthwhile to conduct longitudinal explorations of the effects of both lateral and vertical knowledge inflows on subsidiaries' new product development processes.

Further research might examine how internal subsidiary conditions influence both knowledge integration and the development of innovation abilities. Investigation of knowledge seeking behavior of a subsidiary's members and of its motivation and ability to learn could also provide valuable insights to the knowledge flows process and innovation implications within an MNC.

Moreover, given the non-significant moderator effect of national cultural distance, future research might investigate the national cultural distance effect using alternative measures (e.g. House et al., 2004), since results may differ depending on the national cultural dimensions used. Furthermore, future studies can examine, in an integrated perspective, the influence of both national and organizational cultural distance factors in order to detect possible contradictory effects within MNCs' knowledge transfer process.

Additionally, although we identify and demonstrate the effects of socialization mechanisms on subsidiary knowledge inflows, the use of other mechanisms was not addressed. For example, the reward system of an MNC may affect the communications and information sharing structure between its business units. Subsidiaries may take more initiatives to help each other and disseminate knowledge if their HQ encourages and rewards them for doing so. 


\section{Declaration of competing interest}

None.

\section{Acknowledgements}

\section{This work was supported by FCT, I.P., the Portuguese national funding agency for science, research and technology under the projects UIDB/SOC/04521/2020 and UIDB/04928/2020.}

\section{References}

Achcaoucaou, F., Miravitlles, P., León-Darder, F., 2014. Knowledge sharing and subsidiary R\&D mandate development: a matter of dual embeddedness. Int. Bus. Rev. 23 (1), 76-90.

Alofan, F., Chen, S., Tan, H., 2020. National cultural distance, organizational culture, and adaptation of management innovations in foreign subsidiaries: a fuzzy set analysis of TQM implementation in Saudi Arabia. J. Bus. Res. 109, 184-199.

Ambos, T.C., Birkinshaw, J., 2010. Headquarters' attention and its effect on subsidiary performance. Manag. Int. Rev. 50 (4), $449-469$.

Ambos, T.C., Ambos, B., Schlegelmilch, B.B., 2006. Learning from foreign subsidiaries: an empirical investigation of headquarters' benefits from reverse knowledge transfers. Int. Bus. Rev. 15, 294-312.

Arvanitis, S., Woerter, M., 2009. Firms' transfer strategies with universities and the relationship with firms' innovation performance. Ind. Corp. Chang. 18 (6), 1067-1106.

Bagozzi, R., Yi, Y., 1988. On the evaluation of structural equation models. J. Acad. Mark. Sci. 16, 74-94.

Bai, W., Johanson, M., Martín Martín, O., 2019. Dual business relationships, opportunity knowledge, and new product development: a study on returnee young ventures. J. Int. Mark. 27 (3), 26-42.

Bartlett, C.A., Ghoshal, S., 1989. Managing across Borders: The Transnational Solution: Harvard Business School Press. MA, Boston.

Bartlett, C.A., Ghoshal, S., 1993. Beyond the M-form: toward a managerial theory of the firm. Strateg. Manag. J. 14 (Special Issue), $23-46$.

Birkinshaw, J.M., Morrison, A.J., 1995. Configurations of strategy and structure in subsidiaries of multinational corporations. J. Int. Bus. Stud. 26 (4), $729-753$.

Birkinshaw, J., Hood, N., Jonsson, S., 1998. Building firm-specific advantages in multinational corporations: the role of subsidiary initiative. Strateg. Manag. J. 19, $221-241$.

Björkman, I., Barner-Rasmussen, W., Li, L., 2004. Managing knowledge transfer in MNCs: the impact of headquarters control mechanisms. J. Int. Bus. Stud. 35 (5), $443-455$.

Brislin, R.W., 1980. Translation and content analysis of oral and written material. In: Triandis, H.C., Berry, J.W. (Eds.), Handbook of Cross-cultural Psychology. Allyn \& Bacon, Boston, pp. 389-444.

Brock, J.K., 2003. The 'power' of international business research. J. Int. Bus. Stud. 34 (1), 90-99.

Brock, D.M., Barry, D., Thomas, D.C., 2000. "Your forward is our reverse, your right, our wrong": rethinking multinational planning processes in light of national culture. Int. Bus. Rev. 9 (6), 687-701.

Burmeister, A., Lazarova, M.B., Deller, J., 2018. Repatriate knowledge transfer: antecedents and boundary conditions of a dyadic process. J. World Bus. 53 (6), $806-816$.

Calantone, R.J., Chan, K., Cui, A.S., 2006. Decomposing product innovativeness and its effects on new product success. J. Prod. Innov. Manag. 23 (5), $408-421$.

Cantwell, J., Mudambi, R., 2004. Multinational enterprises and competence-creating knowledge flows: A theoretical analysis. In: Mahnke, Volker, Pedersen, Torben (Eds.), Knowledge Flows, Governance and Multinational Enterprise. Palgrave Macmillan, New York, pp. 38-60.

Capaldo, A., 2007. Network structure and innovation: the leveraging of a dual network as a distinctive relational capability. Strateg. Manag. J. 28 (6), 585-608.

Chin, W., 2010. How to write up and report PLS analyses. In: Vinzi, Chin, Henseler, Wang (Eds.), Handbook of Partial Least Squares: Concepts, Methods And Applications. Springer-Verlag, Berlin, pp. 655-690.

Chin, W.W., Kim, Y.J., Lee, G., 2013. Testing the differential impact of structural paths in PLS analysis: a bootstrapping approach. In: Abdi, H., et al. (Eds.), New Perspectives in Partial Least Squares and Related Methods, Springer Proceedings in Mathematics \& Statistics 56.

Ciabuschi, F., Dellestrand, H., Martín, O.M., 2011. Internal embeddedness, headquarters involvement, and innovation importance in multinational enterprises. J. Manag. Stud. 48 (7), 1612-1639.

Claver-Cortés, E., Zaragoza-Sáez, P., Úbeda-García, M., Marco-Lajara, B., García-Lillo, F., 2018. Strategic knowledge management in subsidiaries and MNC performance. The role of the relational context. J. Knowl. Manag. 22 (5), 1153-1175.

Cohen, J., 1988. Statistical Power Analysis for the Behavioral Sciences. Lawrence Erlbaum, Mahwah, NJ.

Crespo, C.F., Griffith, D.A., Lages, L.F., 2014. The performance effects of vertical and horizontal subsidiary knowledge outflows in multinational corporations. Int. Bus. Rev. 23 (5), 993-1007.

De Luca, L.M., Atuahene-Gima, K., 2007. Market knowledge dimensions and cross-functional collaboration: examining the different routes to product innovation performance. J. Mark. 71 (1), 95-112.

De Mooij, M., Hofstede, G., 2002. Convergence and divergence in consumer behavior: implications for international retailing. J. Retail. 78 (1), 61-69.

Ellis, P.D., 2010. Effect sizes and the interpretation of research results in international business. J. Int. Bus. Stud. 41 (9), 1581-1588.

Falk, R., Miller, N., 1992. A Primer for Soft Modelling, 1st ed. University of Akron Press, Akron, OH.

Faul, F., Erdfelder, E., Buchner, A., Lang, A.-G., 2009. Statistical power analyses using G*power 3.1: tests for correlation and regression analyses. Behavior Research Methods 41, 1149-1160.

Fey, C.F., Furu, P., 2008. Top management incentive compensation and knowledge sharing in multinational corporations. Strateg. Manag. J. 29 (12), 1301-1323. Fornell, C., Larcker, D.F., 1981. Evaluating structural equation models with unobservable variables and measurement error. J. Mark. Res. 18 (1), 39-50.

Foss, N.J., Pedersen, T., 2004. Organizing knowledge processes in the multinational corporation: an introduction. J. Int. Bus. Stud. 35 (5), $340-349$.

Frost, T.S., 2001. The geographic sources of foreign subsidiaries' innovations. Strateg. Manag. J. 22 (2), $101-123$.

Frost, T.S., Birkinshaw, J.M., Prescott, C., 2002. Centers of excellence in multinational corporations. Strateg. Manag. J. 23 (11), $997-1018$.

Garcia-Pont, C., Canales, J.I., Noboa, F., 2009. Subsidiary strategy: the embeddedness component. J. Manag. Stud. 46 (2), $182-214$.

Ghoshal, S., Bartlett, C.A., 1990. The multinational corporation as an interorganizational network. Acad. Manag. Rev. 15 (4), 603-626.

Gölgeci, I., Ferraris, A., Arsland, A., Tarba, S.Y., 2019. European MNE subsidiaries' embeddedness and innovation performance: moderating role of external search depth and breadth. J. Bus. Res. 102, 97-108.

Gong, Y., 2003. Subsidiary staffing in multinational enterprises: agency, resources, and performance. Acad. Manag. J. 46 (6), $728-739$.

Grant, R.M., 1996. Toward a knowledge-based theory of the firm. Strategic Management Journal 17 (Winter Special Issue), 109-122.

Gupta, A.K., Govindarajan, V., 2000. Knowledge flows within multinational corporations. Strateg. Manag. J. 21 (4), 473-496.

Gupta, A.K., Govindarajan, V., Malhotra, A., 1999. Feedback-seeking behavior within multinational corporations. Strateg. Manag. J. 20 (3), $205-222$.

Hair, J., Black, W., Babin, B., Anderson, R., Tatham, R., 2009. Multivariate Data Analysis (Prentice Hall).

Hair, J.F., Sarstedt, M., Ringle, C.M., Mena, J.A., 2012. An assessment of the use of partial least squares structural equation modeling in marketing research. J. Acad. Mark. Sci. 40 (3), 414-433.

Hansen, M.T., 1999. The search-transfer problem: the role of weak ties in sharing knowledge across organization subunits. Adm. Sci. Q. 44 (1), 82. 
Hansen, M.T., Lovas, B., 2004. How do multinational companies leverage technological competencies? Moving from single to interdependent explanations. Strateg. Manag. J. 25 (8-9), 801-822.

Hansen, U.E., Larsen, T.H., Bhasin, S., Burgers, R., Larsen, H., 2020. Innovation capability building in subsidiaries of multinational companies in emerging economies: insights from the wind turbine industry. J. Clean. Prod. 244, 118746.

Harzing, A.-W., 2005. Does the use of english-language questionnaires in cross-national research obscure National Differences? Int. J. Cross-cult. Manag. 5 (2), 213-224.

Hedlund, G., 1986. The hypermodern MNC-a heterarchy? Hum. Resour. Manag. 25, 9-25.

Henseler, J., Dijkstra, T., Sarstedt, M., Ringle, C., Diamantopoulos, A., Straub, D., Ketchen Jr., D.J., Hair, J.F., Hult, G.T.M., Calantone, R., 2014. Common beliefs and reality about PLS. Organ. Res. Methods 17, 182-209.

Hofstede, G., 1980. Culture's consequences: international differences in work-related values. SAGE Publications.

Hong, J.F.L., Nguyen, T.V., 2009. Knowledge embeddedness and the transfer mechanisms in multinational corporations. J. World Bus. 44 (4), $347-356$.

Horwitz, F.M., Kamoche, K., Chew, I.K., 2002. Looking east: diffusing high performance work practices in the southern afro-Asian context. Int. J. Hum. Resour. Manag. 13 (7), 1019-1041.

House, R.J., Hanges, P.W., Javidan, M., Dorfman, P., Gupta, V., 2004. Culture, Leadership, and Organizations: The GLOBE Study of62 Societies. Sage, Beverly Hills.

Hu, L.T., Bentler, P., 1999. Cutoff criteria for fit indexes in covariance structure analysis: conventional criteria versus new alternatives. Struct. Equ. Model. Multidiscip. J. 6 (1), 1-55.

Inkpen, A.C., Tsang, E.W.K., 2005. Social capital, networks and knowledge transfer. Acad. Manag. Rev. 30 (1), $146-165$.

Kogut, B., Singh, H., 1988. The effect of national culture on the choice of entry mode. J. Int. Bus. Stud. 19 (3), $411-432$.

Kogut, B., Zander, U., 1993. Knowledge of the firm and the evolutionary theory of the multinational corporation. J. Int. Bus. Stud. 24 (4), $625-645$.

Kotabe, M., Dunlap-Hinkler, D., Parente, R., Mishra, H.A., 2007. Determinants of cross-national knowledge transfer and its effect on firm innovation. J. Int. Bus. Stud. 38 (2), 259-282.

Kumar, N., 2013. Managing reverse knowledge flow in multinational corporations. J. Knowl. Manag. 17 (5), $695-708$.

Lee, R.P., 2010. Extending the environment-strategy-performance framework: the roles of multinational corporation network strength, market responsiveness, and product innovation. J. Int. Mark. 18 (4), 58-73.

Lee, R.P., Chen, Q., Kim, D., Johnson, J.L., 2008. Knowledge transfer between multinational corporations' headquarters and their subsidiaries: influences on and implications for new product outcomes. J. Int. Mark. 16 (2), 1-31.

Li, J., Lee, R.P., 2015. Can knowledge transfer within MNCs hurt subsidiary performance? The role of subsidiary entrepreneurial culture and capabilities. J. World Bus. 50 (4), 663-673.

Lindell, M.K., Whitney, D.J., 2001. Accounting for common method variance in cross-sectional research designs. J. Appl. Psychol. 86 (1), $114-121$.

Luo, Y., 2005. Toward coopetition within a multinational enterprise: a perspective from foreign subsidiaries. J. World Bus. 40 (1), $71-90$.

Luo, Y., Shenkar, O., Nyaw, M.-K., 2001. A dual parent perspective on control and performance in international joint ventures: lessons from a developing economy. J. Int. Bus. Stud. 32 (1), 41-58.

Lyles, M.A., Salk, J.E., 2007. Knowledge acquisition from foreign parents in international joint ventures: an empirical examination in the Hungarian context. J. Int. Bus. Stud. 38 (1), 3-18.

Madhavan, R., Grover, R., 1998. From embedded knowledge to embodied knowledge: new product development as knowledge management. J. Mark. 62 (October), $1-12$.

Mäkelä, K., Andersson, U., Seppälä, T., 2012. Interpersonal similarity and knowledge sharing within multinational organizations. Int. Bus. Rev. 21 (3), 439-451.

Michailova, S., Mustaffa, Z., 2012. Subsidiary knowledge flows in multinational corporations: research accomplishments, gaps, and opportunities. J. World Bus. 47 (3), 383-396.

Michailova, S., Zhan, W., 2015. Dynamic capabilities and innovation in MNC subsidiaries. J. World Bus. 50 (3), $576-583$.

Monteiro, L.F., Arvidsson, N., Birkinshaw, J., 2008. Knowledge flows within multinational corporations: explaining subsidiary isolation and its performance implications. Organ. Sci. 9 (1), 90-107.

Moore, K.J., 2001. A strategy for subsidiaries: centres of excellences to build subsidiary specific advantages. MIR: Management International Review 41 (3), 275-290.

Morgan, N.A., Kaleka, A., Katsikeas, C.S., 2004. Antecedents of export venture performance: a theoretical model and empirical assessment. J. Mark. 68 (1), 90-108.

Mudambi, R., 2002. Knowledge management in multinational firms. J. Int. Manag. 8 (1), 1-9.

Mullen, M.R., 1995. Diagnosing measurement equivalence in cross-national research. J. Int. Bus. Stud. 26 (3), $573-596$.

Najafi-Tavani, Z., Zaefarian, G., Henneberg, S.C., Naudé, P., Giroud, A., Andersson, U., 2015. Subsidiary knowledge development in knowledge-intensive business services: a configuration approach. J. Int. Mark. 23 (4), 22-43.

Najafi-Tavani, Z., Robson, M., Zaefarian, G., Andersson, U., Yu, C., 2018. Building subsidiary local responsiveness: (when) does the directionality of intrafirm knowledge transfers matter? J. World Bus. 53 (4), 475-492.

Nonaka, I., 1991. The knowledge-creating company. Harv. Bus. Rev. 69 (6), 96-104.

Noorderhaven, N., Harzing, A.-W., 2009. Knowledge-sharing and social interaction within MNEs. J. Int. Bus. Stud. 40 (5), $719-741$.

O'Donnell, S.W., 2000. Managing foreign subsidiaries: agents of headquarters, or an interdependent network? Strateg. Manag. J. 21 (5), 525-548.

Paterson, S.L., Brock, D.M., 2002. The development of subsidiary-management research: review and theoretical analysis. Int. Bus. Rev. 11 (2), $139-163$.

Podsakoff, P.M., 2003. Common method biases in behavioral research: a critical review of the literature and recommended remedies. J. Appl. Psychol. 88 (5), 879-903.

Powell, K.S., Lim, E., 2017. Investment motive as a moderator of cultural-distance and relative knowledge relationships with foreign subsidiary ownership structure. J. Bus. Res. 70, 255-262.

Prabhu, J.C., Chandy, R.K., Ellis, M.E., 2005. The impact of acquisitions on innovation: poison pill, placebo, or tonic? J. Mark. 69 (1), 114-130.

Qin, C., Wang, Y., Ramburuth, P., 2017. The impact of knowledge transfer on MNC subsidiary performance: does cultural distance matter? Knowledge Management Research \& Practice. 15 (1), 78-89.

Reinartz, W., Haenlein, M., Henseler, J., 2009. An empirical comparison of the efficacy of covariance-based and variance-based SEM. Int. J. Res. Mark. 26 (4), 332-344.

Ringle, C.M., Wende, S., Becker, J.-M., 2015. Smart PLS 3. Boenningstedt: smart PLS GmbH. Http://www.

Roth, M.S., Jayachandran, S., Dakhli, M., Colton, D.A., 2009. Subsidiary use of foreign marketing knowledge. J. Int. Mark. 17 (1), $1-29$.

Rugman, A.M., Verbeke, A., 2001. Subsidiary-specific advantages in multinational enterprises. Strateg. Manag. J. 22 (3), $237-250$.

Scott-Kennel, J., Saittakari, I., 2019. Sourcing or sharing in MNE networks? National headquarters and foreign subsidiaries as knowledge conduits in SMOPECs. International Business Review 1-16.

Sheng, M.L., Hartmann, N.N., 2019. Impact of subsidiaries' cross-border knowledge tacitness shared and social capital on MNCs' explorative and exploitative innovation capability. Journal of International Management 1-16.

Sheng, M.L., Hartmann, N.N., Chen, Q., Chen, I., 2015. The synergetic effect of multinational corporation Management's social cognitive capability on tacitknowledge management: product innovation ability insights from Asia. J. Int. Mark. 23 (2), 94-110.

Sivadas, E., Dwyer, R.R., 2000. An examination of organizational factors influencing new product success in internal and alliance-based processes. J. Mark. 64, 31-49.

Sousa, C.M., Tan, Q., 2015. Exit from a foreign market: do poor performance, strategic fit, cultural distance, and international experience matter? J. Int. Mark. 23 (4), 84-104.

Teece, D.J., Pisano, G., Shuen, A., 1997. Dynamic capabilities and strategic management. Strateg. Manag. J. 18 (7), $509-533$.

Vaara, E., Sarala, R., Stahl, G.K., Björkman, I., 2012. The impact of organizational and national cultural differences on social conflict and knowledge transfer in international acquisitions. J. Manag. Stud. 49 (1), 1-27. 
Vaccaro, A., Parente, R., Veloso, F.M., 2010. Technological forecasting \& social change knowledge management tools, inter-organizational relationships, innovation and firm performance. Technological Forecasting \& Social Change 77 (7), 1076-1089.

van Wijk, R., Jansen, J.J.P., van den Bosch, F.A.J., Volberda, H.W., 2012. How firms shape knowledge to explore and exploit: a study of knowledge flows, knowledge stocks and innovative performance across units. Technology Analysis and Strategic Management 24 (9), 929-950.

White III, G.O., Hadjimarcou, J., Fainshmidt, S., Posthuma, R.A., 2013. MNE home country cultural norms and conflict strategy fit in transnational business contract disputes. Int. Bus. Rev. 22 (3), 554-567.

Yamin, M., Andersson, U., 2011. Subsidiary importance in the MNC: what role does internal embeddedness play? Int. Bus. Rev. 20, $151-162$.

Yang, D., Jin, L., Sheng, S., 2017. The effect of knowledge breadth and depth on new product performance. Int. J. Mark. Res. 59 (4), 517-536.

Zeng, R., Grøgaard, B., Steel, P., 2018. Complements or substitutes? A meta-analysis of the role of integration mechanisms for knowledge transfer in the MNE network. J. World Bus. 53 (4), 415-432.

Zhan, G., 2013. Statistical power in international business research: study levels and data types. Int. Bus. Rev. 22 (4), 678-686.

Zhang, J., Di Benedetto, C.A., Hoenig, S., 2009. Product development strategy, product innovation performance, and the mediating role of knowledge utilization: evidence from subsidiaries in China. J. Int. Mark. 17 (2), 42-58.

Zhang, F., Jiang, G., Cantwell, J.A., 2019. Geographically dispersed technological capability building and MNC innovative performance: the role of intra-firm flows of newly absorbed knowledge. J. Int. Manag. 23 (3), 1-18.

Zhou, K.Z., Li, C.B., 2012. How knowledge affects radical innovation: knowledge base, market knowledge acquisition, and internal knowledge sharing. Strateg. Manag. J. 33 (9). 